\title{
BMJ Open Effect of high-intensity exercise on cardiorespiratory fitness, cardiovascular disease risk and disease activity in patients with inflammatory joint disease: protocol for the ExeHeart randomised controlled trial
}

Kristine Røren Nordén (D) , ${ }^{1,2}$ Hanne Dagfinrud, ${ }^{1,2}$ Anne Grete Semb, ${ }^{3}$ Jonny Hisdal, ${ }^{4}$ Kirsten K Viktil, ${ }^{5,6}$ Joseph Sexton, ${ }^{7}$ Camilla Fongen, ${ }^{1}$ Jon Skandsen, ${ }^{8}$ Thalita Blanck, ${ }^{8}$ George S Metsios, ${ }^{9}$ Anne Therese Tveter ${ }^{1}$

To cite: Nordén KR, Dagfinrud H, Semb AG, et al. Effect of high-intensity exercise on cardiorespiratory fitness, cardiovascular disease risk and disease activity in patients with inflammatory joint disease: protocol for the ExeHeart randomised controlled trial. BMJ Open 2022;12:e058634. doi:10.1136/ bmjopen-2021-058634

- Prepublication history and additional supplemental material for this paper are available online. To view these files, please visit the journal online (http://dx.doi.org/10.1136/ bmjopen-2021-058634)

Received 22 0ctober 2021 Accepted 28 January 2022

D) Check for updates

(c) Author(s) (or their employer(s)) 2022. Re-use permitted under CC BY-NC. No commercial re-use. See rights and permissions. Published by BMJ.

For numbered affiliations see end of article.

Correspondence to Kristine Røren Nordén; kristineroren.norden@ diakonsyk.no

\section{ABSTRACT}

Introduction Inflammatory joint disease (IJD) is associated with increased risk of cardiovascular disease (CVD) fostered by systemic inflammation and a high prevalence of CVD risk factors. Cardiorespiratory fitness (CRF) is an important health parameter and CRF-measures are advocated in routine health evaluations. CRF associates with CVD risk, and exercise modalities such as high intensity interval training (HIIT) can increase CRF and mitigate CVD risk factors. In IJD, exercise is rarely used in CVD risk management and the cardioprotective effect of HIIT is unclear. Furthermore, the clinical applicability of HIIT to primary care settings is largely unknown and warrants investigation. The primary aim is to assess the effect of a HIIT programme on CRF in patients with IJD. Second, we will evaluate the effect of HIIT on CVD risk and disease activity in patients with IJD, feasibility of HIIT in primary care and validity of non-exercise algorithms to detect change in CRF.

Methods and analysis ExeHeart is a single-blinded, randomised controlled trial. Sixty patients with IJD will be recruited from the Preventive Cardio-Rheuma clinic at Diakonhjemmet Hospital, Norway. Patients will be assigned to receive standard care (relevant lifestyle advice and cardio-preventive medication) or standard care plus a 12-week HIIT intervention by physiotherapists in primary care. HIIT sessions will be prescribed at $90 \%-95 \%$ of peak heart rate. Outcomes include CRF (primary outcome), CVD risk factors, anthropometric measures, disease activity and patient-reported outcomes related to pain, fatigue, disease, physical activity and exercise and will be assessed at baseline, 3 months (primary endpoint) and 6 months postbaseline.

Ethics and dissemination Ethical approval has been obtained from the Regional Committee for Medical and Health Research Ethics (201227). Participants are required to sign a written informed consent form. Results will be discussed with patient representatives, submitted to peerreviewed journals and presented at relevant platforms. Trial registration number NCT04922840.
Strengths and limitations of this study

The ExeHeart trial is developed in collaboration with patient research partners and aligns with patient's requests of viable, non-pharmacological treatment alternatives in inflammatory joint disease.

- The high-intensity exercise intervention is set in physiotherapy primary care, thereby strengthening the generalisability of trial results to daily clinical care.

- Robust randomised controlled design with repeated assessment of outcome measures by renowned methods is a strength.

- Limited by the use of only one exercise modality and effect sizes are not transferable to endurance exercise at other intensities.

- Non-blinding of patients to study hypothesis and the use of a cardiopulmonary exercise test can prompt changes in physical activity behaviour and diminish group differences at follow-up assessments and is considered a limitation.

\section{INTRODUCTION}

Inflammatory joint diseases (IJD), including rheumatoid arthritis (RA), spondyloarthritis (SpA) and psoriatic arthritis (PsA), are inflammatory autoimmune diseases with common traits of joint inflammation, pain, stiffness, fatigue and reduced physical function. ${ }^{12}$ Compared to the general population, individuals with IJD have an increased risk of cardiovascular disease (CVD).$^{3-5}$ Systemic inflammation can accelerate processes that lead to atherosclerosis and chronic inflammation, and this has been identified as an independent risk factor of CVD. ${ }^{67}$ The elevated CVD risk is also attributed to a higher 
prevalence and burden of traditional risk factors such as hypertension, obesity and hyperlipidaemia. ${ }^{8-10}$ Furthermore, cardiorespiratory fitness (CRF) is recognised as a clinically important variable given that low levels of CRF are associated with higher risk of CVD and all-cause mortality. ${ }^{11}$ Inferior levels of physical activity and CRF are reported in patients with $\mathrm{IJD}^{12}{ }^{13}$ and may serve as a further catalyst in the elevated CVD risk for this patient group. ${ }^{1415}$ Implementation of interventions that can mitigate both systemic inflammation and prevalent CVD risk factors is therefore essential to reduce the risk of CVD in patients with IJD. ${ }^{8}$

CVD prevention in patients with IJD is advocated and the European Alliance of Associations for Rheumatology (EULAR) advises routine CVD screening for patients with IJD. ${ }^{3}$ Despite increased awareness of excess CVD risk, management is often suboptimal and CVD risk factors are frequently non-recorded and undertreated in patients with IJD. ${ }^{16}{ }^{17}$ Common CVD risk prediction models underestimate the risk of CVD in the context of $\mathrm{IJD},{ }^{18}$ a fact that accentuates the need for additional health measures to optimise CVD risk evaluation in this high-risk population. ${ }^{16}$ Routine assessment of CRF as a clinical vital sign is recommended, but seldom performed in outpatient settings. However, user-friendly, non-exercise algorithms to estimate CRF (eCRF) are available and can potentially be used to measure the effect of health-enhancing interventions in IJD care. ${ }^{11} 19$

Physical activity is currently included in guidelines on primary and secondary prevention of CVD and individuals presenting with CVD as primary diagnosis are often referred to exercise as an integral part of disease management. ${ }^{720}$ However, exercise is underutilised as a core component of CVD risk management in patients with IJD and seldom implemented in clinical healthcare. $^{21} 22$ Previous hesitancy regarding the safety of vigorous exercise has led to rather conservative dosage of exercise intensity in IJD, but recent studies demonstrate that vigorous exercise is safe and does not inflict disease flares in patients with IJD. ${ }^{23-25}$ Research even indicates that exercise may promote an anti-inflammatory milieu, although additional studies are required to conclude on the exercise-induced effect on inflammation in the presence of IJD. ${ }^{26} 27$

Exercise has a dose-dependent effect on health outcomes and high-intensity interval training (HIIT) has emerged as a form of exercise that is proven superior to exercise at lower intensities in improving CRF. ${ }^{28}{ }^{29}$ This time-efficient exercise mode alternates between bouts of high intensity exercise interspaced with bouts of lower intensity. Beneficial health outcomes of HIIT have been reported in various patient populations, but additional studies are needed to safely recommend HIIT as a cardioprotective mode of exercise in patients with IJD. ${ }^{30}{ }^{31}$ Notably, HIIT interventions are often delivered under stringent research designs or with care providers that are extensively trained in the patient group at hand. This has cast doubt on the applicability of HIIT in real world contexts and studies evaluating the effect of HIIT in routine clinical care are currently needed. ${ }^{32}$

\section{Aim}

The primary aim of the ExeHeart trial is to determine the effect of a 12-week HIIT programme set in physiotherapy primary care on CRF in patients with IJD.

Secondary aims of the trial are to (1) assess the effect of HIIT on traditional CVD risk factors and disease activity in patients with IJD, (2) assess the association between CRF and disease-specific and CVD-related variables in IJD, (3) explore the feasibility of a HIIT intervention set in physiotherapy primary care in terms of patient's adherence and tolerability to the exercise programme and (4) report on the validity of eCRF algorithms to accurately detect potential changes in CRF.

\section{Hypotheses}

We hypothesise that the HIIT intervention set in primary care will increase CRF and be associated with a concurrent decrease in traditional CVD risk factors. We do not expect any increase in disease activity due to HIIT. The HIIT intervention in primary care is hypothesised to be feasible measured by patient adherence and tolerability. Finally, we hypothesise that eCRF can detect meaningful change in CRF.

\section{METHODS AND ANALYSIS}

\section{Trial design and study setting}

ExeHeart is a parallel group, randomised controlled superiority trial with repeated measures. Patients will be randomly allocated to (1) Current clinical practice including CVD risk evaluation, lifestyle advice given at baseline and relevant cardioprotective medication (control group) or (2) Current clinical practice and a 12-week HIIT intervention. The HIIT intervention will be supervised by experienced and licensed physiotherapists at primary care clinics in the municipality of Oslo, Norway.

Patients will be recruited from the Preventive CardioRheuma clinic, an outpatient clinic housed by the Department of Rheumatology and Research at Diakonhjemmet Hospital, Oslo, Norway. Referral criteria to the Preventive Cardio-Rheuma clinic are (1) Patient with IJD requesting a CVD risk evaluation, (2) Physician or patient are aware of the presence of $\geq 1$ CVD risk factors, (3) Patient with symptoms consistent with CVD risk factors, for example, headache due to increased blood pressure and/or (4) Patient with a family history of premature CVD. ${ }^{33}$

\section{Project timeline}

Enrolment was initiated in August 2021 and will continue until target sample size is reached, presumably by October 2022. Participant flow is illustrated in figure 1 . The unpredictable course of the ongoing SARS-CoV-2 pandemic may impact national healthcare systems and influence the ExeHeart trial progress. At baseline, measurements will 


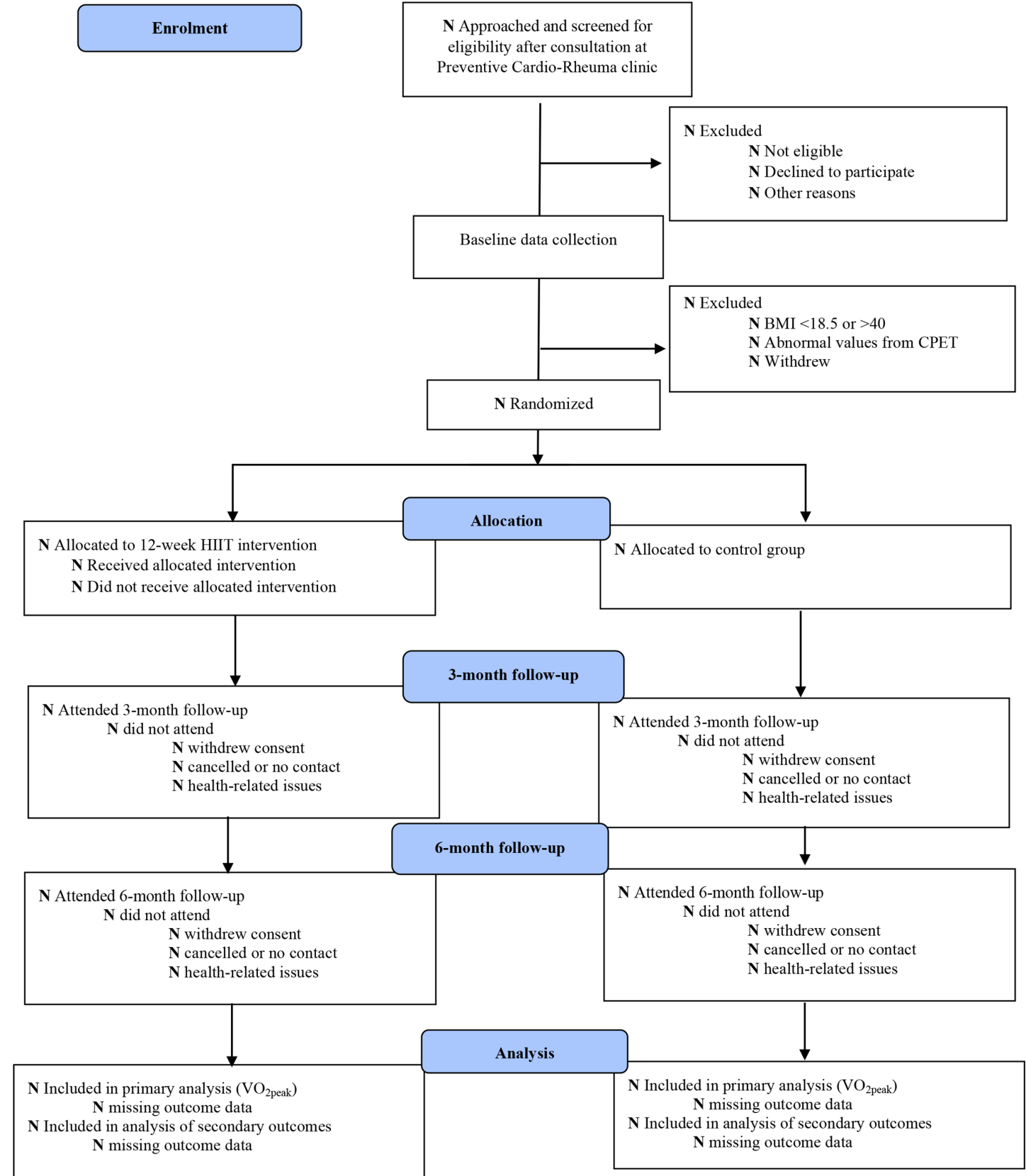

Figure 1 Exeheart trial flow chart. BMI, body mass index; CPET, cardiopulmonary Exercise test; HIIT, high-intensity interval training; $\mathrm{VO}_{2 \text { peak }}$, peak oxygen uptake.

be collected from the patient's consultation at the Preventive Cardio-Rheuma clinic (prebaseline), digital questionnaires and a baseline clinical test session at the outpatient clinic at Diakonhjemmet Hospital. The full test protocol will be repeated at follow-up sessions that are scheduled 3 months and 6 months after baseline assessment.

\section{Sample size}

Sample size is calculated on the basis of the primary outcome variable, where a between-group difference in peak oxygen uptake $\left(\mathrm{VO}_{2 \text { peak }}\right)$ of $3.5 \mathrm{~mL} / \mathrm{kg} / \mathrm{min}$ is considered to be of clinical relevance. ${ }^{20}$ Using a reported upper bound of 4.5 on the $\mathrm{SD}$ of change in $\mathrm{VO}_{2 \text { peak }} 34$ and $80 \%$ power to detect this difference, approximately 25 participants are required in each group. To allow for a possible $20 \%$ drop-out rate, we plan to randomise 60 patients in total (ie, 30 per group).

\section{Eligibility criteria and patient screening}

Patients will receive a cardiovascular risk evaluation by a cardiologist (AGS) at the Preventive Cardio-Rheuma clinic and be assessed for trial eligibility based on age, diagnosis and cardiovascular suitability to maximal exercise testing. Subsequently, patients will be contacted by an ExeHeart project group member and provided oral and written information regarding the purpose and requirements of the study. Patients will be screened thoroughly according to inclusion and exclusion criteria, including American College of Sports Medicine guidelines for exercise testing $^{20}$ (table 1). Eligible patients will be invited to 
Table 1 ExeHeart inclusion and exclusion criteria

\begin{tabular}{ll}
\hline Inclusion criteria & Exclusion criteria \\
\hline Age $18-70$ years old at & Sustained lower extremity \\
baseline & injury $\leq 12$ months, including \\
BMI: $18.5-40 \mathrm{~kg} / \mathrm{m}^{2}$ & surgery \\
IJD disease verified by & Primary neurological disease \\
rheumatologist & Contraindication to maximal \\
Able to walk unaided and & exercise test ${ }^{20}$ \\
continuously for $\geq 15$ min & Cognitive disability \\
Norwegian or English & Participation in structured \\
speaking & HIIT $\geq 1 /$ week the last 3 months \\
\hline
\end{tabular}

BMI, body mass index; HIIT, High-Intensity Interval Training; IJD, inflammatory joint disease.

enrol in the study and sign an informed consent form on acceptance of participation (online supplemental files A and $\mathrm{B})$.

\section{Outcome measures}

The primary outcome measure is CRF at 3-month follow-up, measured as $\mathrm{VO}_{\text {2peak }}$ in $\mathrm{mL} / \mathrm{kg} / \mathrm{min}$ by a cardiopulmonary exercise test (CPET).

Secondary outcome measures comprise disease activity, blood pressure, blood lipids, body mass index, body composition, arterial stiffness, resting heart rate (HR), Systemic COronary Risk Estimation 2 (SCORE2), additional markers of CRF derived from CPET (table 2) and patient self-report of pain, fatigue, cardiovascular health, medication and domains related to physical activity and exercise (table 3 ).

\section{Cardiopulmonary exercise test}

The CPET will be performed by use of a breath-bybreath gas analysing system (Vyntus CPX, Vyaire Medial, Hoechenberg, Germany) with gas calibration every third hour, automatic volume sensor calibration between each subject and weekly manual calibration of volume sensors by a $3 \mathrm{~L}$ syringe (Hans Rudolph, Shawnee, USA) ${ }^{35}$

To start with, pulmonary function will be assessed by spirometer according to guidelines ${ }^{36}$ and forced expiratory volume (FEV1, L), forced vital capacity (L) and peak expiratory flow $(\mathrm{L} / \mathrm{min})$ will be recorded from three attempts at maximal expiratory flow volume loops. Maximal voluntary ventilation $(\mathrm{MVV}, \mathrm{L} / \mathrm{min}$ ) will be measured twice by breathing deeply and rapidly for 12 s. In cases of poor technique, MVV will be estimated as FEV1×37.5 (35).

The CPET will be performed on a treadmill (PPS 55 Woodway, Würzburg, Germany) with 12-lead ECG (Customed cardio 300 BT_A, CareFusion, Ottobrunn, Germany), blood pressure monitor (Suntech Tango M2, SunTech Medical, Morrisville, USA), pulse oximetry and modified Borg rating of perceived exertion (Borg RPE 1-10). ${ }^{37}$ Gas exchange is measured breath-by-breath and averaged over eight breaths throughout the test with patients breathing into a Hans Rudolph two-way mask (7450 series, Hans Rudolph, Shawnee, USA). A modified Balke ramp protocol is used with initial treadmill speed individually set based on estimated functional capacity. ${ }^{38}$ Patients unaccustomed to treadmill walking will be familiarised with the treadmill before the test starts. The test is completed when the participant is unable to continue despite verbal encouragement from the test technician. The protocol is terminated in advance of exhaustion if the test technician observes abnormal and/ or adverse test values or the patient requests to stop. ${ }^{20}$ Peak HR $\left(\mathrm{HR}_{\text {peak }}\right)$ is recorded at maximal exercise level. Blood lactate concentration is sampled within $60 \mathrm{~s}$ of test completion to evaluate level of anaerobic processes (Lactate Scout 4, SensLab, Leipzig, Germany). Borg RPE $0-10, \mathrm{HR}_{\text {peak }}$, respiratory exchange ratio and post-exercise blood lactate concentration are used to assess level of effort. ${ }^{39}$ Additional parameters collected from CPET are ventilatory thresholds, breathing reserve at peak exercise, oxygen pulse as well as ventilatory equivalents for oxygen and carbon dioxide. ${ }^{11}$

\section{Traditional CVD risk factors}

Medical background information will be collected from the patient's journal recorded at the prebaseline consultation at the Preventive Cardio-Rheuma clinic. Non-fasting blood samples will be measured at the hospital laboratory (European Standard Accredited 2009) by routine procedures (Cobas 8000, F. Hoffmann-La Roche, Basel, Switzerland) ${ }^{40}$ and analysed for $\mathrm{C}$ reactive protein (CRP), erythrocyte sedimentation rate (ESR), total cholesterol, high-density lipoprotein (HDL), low-density lipoprotein and triglycerides. Blood pressure, resting HR, and arterial stiffness (measured as augmentation index and pulse wave velocity) will be measured after the patient has been in a supine position for at least $10 \mathrm{~min}$ in a semi dark room, using an ambulatory blood pressure monitor (Mobil-o-graph PWA, I.E.M., Stolberg, Germany). Twelvelead resting ECG will be recorded (CAM 14, GE Medical Systems Information Technologies, Wisconsin, USA). SCORE2 will be calculated with variables gender, age, nonHDL cholesterol, systolic blood pressure and smoking status. ${ }^{7}$ As recommended by EULAR, a 1.5 multiplication factor will be included for patients presenting with RA. ${ }^{3}$

\section{Anthropometric measures}

Patients will be asked to be 2 hours postprandial and to refrain from using caffeine and/or nicotine the last 4 hours prior to study visits. Body height will be measured by wall ruler (KaWe Person Check, Kirchner \& Wilhelm+Co. KG, Asperg, Germany). Body weight and body composition will be measured by bioelectrical impedance analysis (Tanita MC-780MA and Tanita Gmon Software Pro, Tanita, Tokyo, Japan). Waist circumference will be measured horizontally at the level of the iliac crest with the patient in a standing position. ${ }^{20}$

\section{Disease activity}

Disease activity will be measured by inflammatory markers CRP and ESR and with instruments according to IJD entity; Disease Activity Score-28 Calculator for RA 
Table 2 Data collection-clinical outcome measures

\section{Cardiopulmonary exercise test}

\begin{tabular}{lll}
\hline Outcome & Comment & Time point \\
\hline Forced expiratory volume (L) & Three attempts & Baseline, 3months, 6months \\
\hline Forced vital capacity (L) & Three attempts & Baseline, 3months, 6months \\
Peak expiratory flow (L/min) & Three attempts & Baseline, 3months, 6months \\
$\begin{array}{l}\text { Maximal voluntary ventilation (MVV, L/ } \\
\text { min) }\end{array}$ & Two attempts & Baseline, 3months, 6months
\end{tabular}

$\min$ )

Peak oxygen uptake $\left(\mathrm{VO}_{\text {2peak }}, \mathrm{mL} / \mathrm{kg} / \mathrm{min}\right.$ and $L /$ min)

Peak HR (HR peak , beat $/$ min)

Ventilatory threshold 1

Baseline, 3months, 6months

Ventilatory threshold 2

$\mathrm{VO}_{2}(\mathrm{~mL} / \mathrm{kg} / \mathrm{min})$ and $\mathrm{HR}$ are recorded

Baseline, 3months, 6months

$\mathrm{VO}_{2}(\mathrm{~mL} / \mathrm{kg} / \mathrm{min} /)$ and $\mathrm{HR}$ are recorded

Baseline, 3months, 6months

Maximum minute ventilation at peak

exercise $\left(\mathrm{VE}_{\max }\right.$, L/min)

Breathing reserve at peak exercise (\%)

Difference between MVV and the maximum ventilation measured during CPET

Baseline, 3months, 6months

Baseline, 3months, 6months

Baseline, 3months, 6months

$\mathrm{VO}_{2} / \mathrm{HR}$, represents the product of stroke volume and the Baseline, 3months, 6months arterial-venous oxygen difference

Oxygen pulse at peak exercise $\left(\mathrm{O}_{2}\right.$-pulse,
$\mathrm{mL} /$ beat/min $)$
Ventilatory equivalent for oxygen $\left(\mathrm{V}_{\mathrm{E}} / \mathrm{VO}_{2}\right)$

Ventilatory equivalent for oxygen $\left(\mathrm{V}_{\mathrm{E}} / \mathrm{NO}_{2}\right)$

consumption per minute-registered at ventilatory

threshold 1 and 2

Ventilatory equivalent for carbon dioxide
$\left(\mathrm{V}_{\mathrm{E}} \mathrm{NCO}_{2}\right)$

of the volume of gas expired per minute to $\mathrm{VCO}_{2}$ production per minute-registered at ventilatory threshold 1 and 2

Respiratory exchange ratio $\quad \mathrm{VCO}_{2} \mathrm{NO}_{2}$, recorded at peak exercise

Postexercise blood lactate concentration ( $\mathrm{mmol} / \mathrm{L})$

Borg RPE At peak exercise, 0-10

\section{CVD risk factors}

\begin{tabular}{|c|c|c|}
\hline Outcome & Comment & Time point \\
\hline $\begin{array}{l}\text { Blood samples } \\
\text { CRP (mg/L) } \\
\text { ESR (mm) } \\
\text { Total cholesterol (mmol/L) } \\
\text { HDL (mmol/L) } \\
\text { LDL (mmol/L) } \\
\text { Triglycerides (mmol/L) }\end{array}$ & Non-fasting & Baseline, 3 months, 6 months \\
\hline Outcome & Comment & Time point \\
\hline Height (cm) & Nearest cm & Baseline, 3months, 6months \\
\hline Body weight (kg) & Nearest $0.1 \mathrm{~kg}$ & Baseline, 3months, 6months \\
\hline Waist circumference (cm) & Mean value of 2 measurements, nearest $0.5 \mathrm{~cm}$ & Baseline, 3months, 6months \\
\hline Fat mass $(\mathrm{kg})$ & Bioelectrical impedance analysis & Baseline, 3months, 6months \\
\hline Fat-free mass (kg) & Bioelectrical impedance analysis & Baseline, 3months, 6months \\
\hline Visceral fat indicator & Bioelectrical impedance analysis & Baseline, 3months, 6months \\
\hline
\end{tabular}

Continued 
Table 2 Continued

\begin{tabular}{|c|c|c|}
\hline \multicolumn{3}{|c|}{ Disease activity } \\
\hline Outcome & Comment & Time point \\
\hline DAS28 & $\begin{array}{l}\text { For patients presenting with RA } \\
\text { No of tender and swollen joints (out of 28), ESR or } \\
\text { CRP and patient global assessment of health on a } \\
100 \mathrm{~mm} \text { Visual Analogue Scale }\end{array}$ & Baseline, 3months, 6 months \\
\hline DAPSA & $\begin{array}{l}\text { For patients presenting with PsA } \\
\text { Numerical sum of tender joints (out of } 68 \text { ), } \\
\text { swollen joints (out of } 66 \text { ), CRP and patient global } \\
\text { assessment of disease activity and pain }\end{array}$ & Baseline, 3months, 6months \\
\hline ASDAS & $\begin{array}{l}\text { For patients presenting with } \mathrm{SpA} \\
\text { Composite measure including patient-reported } \\
\text { back pain, duration of morning stiffness, peripheral } \\
\text { pain, patient global assessment and ESR or CRP }\end{array}$ & Baseline, 3months, 6months \\
\hline
\end{tabular}

ASDAS, Ankylosing Spondylitis Disease Activity Score; Borg RPE, Borg rating of perceived exertion; CRP, C reactive protein; CVD, cardiovascular disease; DAPSA, Disease Activity Index for PSoriatic Arthritis; DAS28, Disease Activity Score-28; ESR, erythrocyte sedimentation rate; HDL, high-density lipoprotein; HR, heart rate; LDL, low-density lipoprotein; RPE, rating of perceived exertion; SCORE2, Systemic COronary Risk Estimation 2; $\mathrm{VCO}_{2}$, volume of carbon dioxide; $\mathrm{V}_{\mathrm{E}}$, minute ventilation; $\mathrm{VO}_{2}$, volume of oxygen.

(DAS28) is used as a measure of overall disease activity in patients presenting with RA, ${ }^{41}$ Disease Activity Index for PSoriatic Arthritis (DAPSA) for patients with PsA ${ }^{42}$ and Ankylosing Spondylitis Disease Activity Score (ASDAS) for patients with SpA. ${ }^{43}$ Instrument-specific thresholds will be applied to provide categories of remission, low, moderate and high disease activity.

\section{Questionnaires}

Prior to all study visits, patients will receive an email with link to an electronic questionnaire created with nettskjema.no, a survey solution developed and hosted by the University of Oslo (nettskjema@usit.uio.no). In cases where response to an electronic questionnaire is not feasible, a paper version will be supplied. The questionnaire includes personal background information, use of medication and healthcare services, pain, fatigue, disease activity, CVD symptoms, physical activity habits, exercise beliefs and self-efficacy of exercise. Questions regarding SARS-CoV-2 infection and/or quarantine, exercise behaviour and perceived change in physical fitness will be included at follow-up time points (table 3 ).

\section{Randomisation and allocation concealment}

Following baseline assessments, patients are allocated 1:1 by a computer-generated randomisation schedule using permuted blocks of random sizes 4 and 6 , stratified by gender. Project leader (ATT) is in charge of telephoning and assigning patients to designated group. The trial is single-blinded with outcome assessors (KRN and $\mathrm{CF}$ ) blinded to group allocation. Patients and physiotherapists in charge of exercise sessions are not blinded to treatment exposure nor study hypothesis.

\section{Intervention}

All patients, regardless of group allocation, will receive standard care following a consultation at the Preventive
Cardio-Rheuma clinic, including CVD risk evaluation, lifestyle advice; heart-healthy diet, regular exercise, weight management and non-smoking given at baseline and prescription of relevant medication at the discretion of the attending physician.

\section{Intervention group (HIIT)}

Patients randomised to the HIIT intervention group will be invited to receive a 12-week exercise intervention with 2 weekly HIIT exercise sessions guided by a physiotherapist at a primary care clinic. The initial 2 weeks of the intervention invites a progressive exercise load, starting from lower intensity and gradually increasing to a HIIT protocol. The HIIT protocol will include a 10 min warmup, followed by $4 \times 4$ min at $90 \%-95 \% \mathrm{HR}_{\text {peak }}$, Borg RPE $16-18,{ }^{37}$ interspaced by $2-3$ min active breaks at $60 \%-70 \%$ $\mathrm{HR}_{\text {peak, }}$, Borg RPE 11-13. Uphill walking or running will be prioritised, but other modes of exercise, such as cycling or elliptical machine may also be used. Exercise work load will be tailored to each individual to provide the same relative exercise stress and to ensure progression. ${ }^{28}$ Target exercise intensity will be monitored by a Polar H10 HR monitor (Polar, Kempele, Finland) connected to the training device or by wrist-based light sensors in Polar Ignite fitness watches (Polar, Kempele, Finland) provided to all HIIT participants. HR will be recorded in a training diary by the physiotherapist at the third minute of each interval bout with patients concurrently registering Borg RPE 6-20. The exercise programme will also include a recommendation for a third weekly, non-supervised exercise session at moderate intensity; 10 min warm-up at Borg RPE 11-12, followed by 30 min endurance exercise at Borg RPE 12-14. In these sessions, patients will be asked to record mean and maximum HR by use of Polar Ignite fitness watch as well as overall Borg RPE in the training diary. 
Table 3 Data collection from digital questionnaires

\section{Questions related to demographic variables and health}

\begin{tabular}{lll}
\hline Topic & Measure & Time point \\
\hline Demography & Relationship status & Baseline \\
& Education & Employment \\
& Years diagnosed with IJD & Baseline, 3months, \\
Health & Smoking and snuff use & 6 months \\
& Use of healthcare services the previous 3 months & \\
& CVD history & CVD symptoms \\
& Use of medication; analgesics, IJD and CVD medication
\end{tabular}

SARS-CoV-2 infection and/or quarantine in the past 3 months

3months, 6months

\begin{tabular}{|c|c|c|}
\hline \multicolumn{3}{|l|}{ Questionnaires } \\
\hline Measure & Domains & Time point \\
\hline Numeric Rating Scales of $0-10$ & $\begin{array}{l}\text { Pain during last week. } \\
\text { Fatigue during last week. }\end{array}$ & $\begin{array}{l}\text { Baseline, 3months, } \\
6 \text { months }\end{array}$ \\
\hline EuroQol-5D-5L ${ }^{5758 *}$ & $\begin{array}{l}\text { Five domains with five response levels: Mobility, self-care, usual activities, pain/ } \\
\text { discomfort, anxiety/depression. }\end{array}$ & $\begin{array}{l}\text { Baseline, 3months, } \\
6 \text { months }\end{array}$ \\
\hline $\begin{array}{l}\text { EuroQol-5D-5L Visual Analogue } \\
\text { Scale* }\end{array}$ & 0 (worst imaginable health)-100 (best imaginable health). & $\begin{array}{l}\text { Baseline, 3months, } \\
6 \text { months }\end{array}$ \\
\hline $\begin{array}{l}\text { Rheumatoid Arthritis Impact of } \\
\text { Disease }\end{array}$ & $\begin{array}{l}\text { For patients presenting with RA } \\
\text { Seven domains: Pain, function, fatigue, physical and emotional well-being, sleep } \\
\text { and coping. Domains are weighted, final score } 0 \text { (best)-10 (worst). }\end{array}$ & $\begin{array}{l}\text { Baseline, 3months, } \\
6 \text { months }\end{array}$ \\
\hline $\begin{array}{l}\text { Psoriatic Arthritis Impact of } \\
\text { Disease }\end{array}$ & $\begin{array}{l}\text { For patients presenting with PsA } \\
\text { Nine domains: Pain, skin, fatigue, work/leisure, function, discomfort, sleep, } \\
\text { anxiety, coping. Domains are weighted, final score } 0 \text { (best)-10 (worst). }\end{array}$ & $\begin{array}{l}\text { Baseline, 3months, } \\
6 \text { months }\end{array}$ \\
\hline $\begin{array}{l}\text { Bath Ankylosing Spondylitis } \\
\text { Functional Index }\end{array}$ & $\begin{array}{l}\text { For patients presenting with SpA } \\
\text { Ten activities scored from } 0 \text { (easy)-10 (impossible). Total score calculated as } \\
\text { mean of all } 10 \text { domains. }\end{array}$ & $\begin{array}{l}\text { Baseline, 3months, } \\
6 \text { months }\end{array}$ \\
\hline $\begin{array}{l}\text { Bath Ankylosing Spondylitis Patient } \\
\text { Global Score }{ }^{61}\end{array}$ & $\begin{array}{l}\text { For patients presenting with SpA } \\
\text { Two questions (past week and past } 6 \text { months): Effect of disease on well-being } \\
\text { ranked } \\
0 \text { (none)-10 (very severe). }\end{array}$ & $\begin{array}{l}\text { Baseline, 3months, } \\
6 \text { months }\end{array}$ \\
\hline $\begin{array}{l}\text { HUNT1 Physical Activity } \\
\text { Questionnaire }^{62}\end{array}$ & $\begin{array}{l}\text { Three questions regarding exercise habits: Frequency, intensity and duration of } \\
\text { exercise. }\end{array}$ & $\begin{array}{l}\text { Baseline, 3months, } \\
6 \text { months }\end{array}$ \\
\hline $\begin{array}{l}\text { Exercise beliefs and exercise } \\
\text { habits }^{63}\end{array}$ & $\begin{array}{l}\text { Four subscales; self-efficacy for exercise (four elements), barriers to exercise } \\
\text { (three elements), benefits of exercise (five elements), and impact of exercise on } \\
\text { IJD (eight elements). Five-point Likert scale: } \\
1 \text { (strongly disagree)- } 5 \text { (strongly agree). }\end{array}$ & $\begin{array}{l}\text { Baseline, 3months, } \\
6 \text { months }\end{array}$ \\
\hline
\end{tabular}

Continued 
Table 3 Continued

\section{Questionnaires}

\begin{tabular}{|c|c|c|}
\hline Measure & Domains & Time point \\
\hline $\begin{array}{l}\text { Self-reported frequency and mode } \\
\text { of exercise }\end{array}$ & $\begin{array}{l}\text { Three questions regarding participation in regular exercise the past } 3 \text { months } \\
\text { (yes/no), frequency and mode of exercise }\end{array}$ & $\begin{array}{l}3 \text { months (control group } \\
\text { participants only), } \\
6 \text { months (all patients) }\end{array}$ \\
\hline COVID-19 infection and quarantine & $\begin{array}{l}\text { Two questions regarding COVID-19 infection and/or quarantine during the past } \\
3 \text { months }\end{array}$ & 3months, 6months \\
\hline
\end{tabular}

*Paper version of questionnaire is used, included at study visits with clinical assessments.

CVD, cardiovascular disease; HIIT, high-intensity training; HUNT, Trøndelag Health Study; IJD, Inflammatory joint disease; PsA, psoriatic arthritis; RA, rheumatoid arthritis; SpA, spondyloarthritis.

\section{Control group}

Patients allocated to the control group will not be discouraged from taking part in regular exercise, but receive no targeted exercise intervention subsequent to baseline measurements. Succeeding the 6-month follow-up session, control group participants will be invited to attend an individual theoretical and practical HIIT session guided by a physiotherapist from the Norwegian National Unit for Rehabilitation for Rheumatic Patients with Special Needs.

\section{Adherence and tolerability}

Adherence to HIIT will be recorded by use of the training diary. Exercise session attendance will be tallied and criteria for adherence is set to $\geq 70 \%(17 / 24)$ of HIIT sessions. HIIT exercise intensity sessions will be calculated as mean \% $\mathrm{HR}_{\text {peak }}$ and Borg RPE 6-20 across sessions and participants. Likewise, duration will be reported as mean session duration and average time spent in high intensity intervals. ${ }^{44}$ Tolerability of HIIT will be explored by clinical measures of disease activity with disease flares defined as increase in DAS28 $>1.2$ or $>0.6$ if DAS28 $\geq 3.2,{ }^{45}$ DAPSA $\geq 7^{46}$ or ASDAS $\geq 0.9 .{ }^{47}$

At the 3-month point, an additional questionnaire will be distributed electronically to patients in the HIIT-group $(\mathrm{n}=30)$, addressing patients' acceptability and satisfaction with the HIIT programme (table 3). This questionnaire is self-developed in collaboration with the patient research partners. The ExeHeart trial will also include semistructured interviews, targeting 5-7 patients in the intervention group. These interviews aim to explore barriers and facilitators in exercise adherence, experience with the HIIT protocol and perceived effects of exercise. The participants will be interviewed by a person unaffiliated to the research group.

\section{Patient safety and adverse events}

Any abnormal values that are observed during clinical assessments throughout the study will be discussed with a cardiologist or rheumatologist as relevant. Patients eligible for inclusion will be examined by a cardiologist during the consultation at the Preventive Cardio-Rheuma clinic and further screened on contraindications to maximal exercise before entering the study. ${ }^{20}$ The CPET will be supervised by physiotherapists (KRN or $\mathrm{CF}$ ) that are trained in exercise physiology, have extensive knowledge of exercise stress tests and sufficient familiarity with indications to terminate a CPET. ${ }^{48}$ In case of an adverse event, the hospital's emergency personnel will be alerted by alarm in accordance to hospital protocol.

Physiotherapists in primary care will be advised to use clinical checklists prior to each HIIT session; patient general well-being, absence of angina, dyspnoea or dizziness and resting HR $<120$. Furthermore, exercise sessions are to be ceased if HR does not increase with a higher workload or if the patient reports symptoms such as chest-pain or light-headedness. ${ }^{49}$ Physiotherapists will be instructed to contact the patient's general practitioner and the project leader (ATT) in case of adverse events or abnormal exercise-related symptoms. Safety of HIIT will be monitored by asking patients and physiotherapists to record any events in the training diary.

\section{Data management}

Encrypted data will be sent from nettskjema.no to Sensitive Data Services (TSD) at the University of Oslo, and downloaded to a secure server at Diakonhjemmet Hospital. Patients case report forms will be secured in locked cabinets according to hospital policy and will remain stored for 5 years after study completion. All data files will be stored in a secure research server at Diakonhjemmet Hospital with access to files restricted to project group members (KRN, HD, AGS, JSe, CF and ATT). Accuracy of data entry will be monitored by verification of a subset of data. Data may be shared on reasonable request to the project manager.

\section{Statistical analysis}

The primary analysis will be a between group comparison of $\mathrm{VO}_{\text {2peak }}(\mathrm{mL} / \mathrm{kg} / \mathrm{min})$. This will be carried out according to the intention-to-treat principle, and done by the analysis of covariance, adjusting for age, $\mathrm{VO}_{2 \text { peak }}$ values at baseline and other relevant factors. Secondary analyses will include between group comparisons on secondary outcomes, as well as comparisons in the per protocol population. Parametric and non-parametric statistical analyses will be carried out as appropriate based on visual inspection of variable distribution. No adjustment for multiple testing will be done. 
The association between $\mathrm{VO}_{2 \text { peak }}$ and changes in disease activity and CVD risk factors will be assessed using multiple linear regression. The validity of eCRF models to accurately detect longitudinal change in $\mathrm{VO}_{2 \text { peak }}$ from baseline to follow-up will be assessed with Pearson or Spearman correlation and illustrated through Bland-Altman plot by comparing CPET-derived $\mathrm{VO}_{2 \text { peak }}$ to eCRF using an algorithm for the general population ${ }^{19}$ and a model for RA populations. ${ }^{50}$ Adherence, tolerability and acceptance of the HIIT protocol will be explored with descriptive statistics.

\section{Ethics and dissemination}

The ExeHeart trial is evaluated and approved by the Regional Committee for Medical and Health Research Ethics (REC south-east 201227) and the Data Protection Officer at Diakonhjemmet Hospital (reg.no. 00397). Any protocol amendments are forwarded to REC and recorded in CinicalTrials.gov.

All procedures will be performed in adherence to the Helsinki declaration. Participants will be provided with written and oral information and asked to sign a consent form before enrolling in the study. No patients will, regardless of group allocation, receive treatment that falls short of standard clinical care. Possible risks that may impair study recruitment and follow-up are insecurities among patients regarding maximal exercise testing. We will assure patients that CPET is a safe procedure with very low risk of adverse events. ${ }^{11}$ To reduce the risk of control group drop-out at repeated measures, we will invite control group participants to a physiotherapist-led theoretical and practical HIIT session following study close-out.

Dissemination of trial results will conform to Consolidated Standards of Reporting Trials guidelines ${ }^{51}$ and Consensus on Exercise Reporting Template. ${ }^{52}$ Results will be presented in international peer-reviewed, open access journals and through relevant communication platforms.

\section{Patient and public involvement}

The ExeHeart trial is developed in agreement with Standard Protocol Items: Recommendations for Interventional Trials guidelines ${ }^{53}$ and designed in collaboration with the Norwegian Rheumatism Association and patient research partners to enhance the relevance of research questions and feasibility of methods. Two experienced patient research partners from the Patient advisory board at Diakonhjemmet Hospital have been involved in the planning of ExeHeart and will contribute in all further phases of the trial.

\section{DISCUSSION}

Despite compelling evidence of the potential of correctly dosed exercise in mitigating risk of disease, exercise is underutilized in CVD risk management in $\mathrm{IJD}^{21}{ }^{21} \mathrm{We}$ expect that the results of the ExeHeart trial will shed light on the effect and feasibility of HIIT in mitigating CVD risk in patients with IJD. If the results show favourable effects on CRF and few side effects, HIIT can be advocated as a safe and time-efficient mode of exercise for patients with IJD. Additionally, if eCRF models are deemed adequate in detecting change in CRF, future implementation of eCRF to clinical care may aid practitioners in accurately stratifying CVD risk.

Strengths of the study are the randomised controlled design, comprehensive clinical CVD risk assessments and blinding of outcome assessors. Furthermore, our trial is developed in close collaboration with patient research partners and aims to meet patient requests of effective, non-pharmacological treatment alternatives.

There are some limitations to our trial. Despite random allocation to HIIT, comparator contamination is plausible. Comprehensive health assessments, including a CPET, may reassure patients that exercise is safe and prompt physical behavioural changes to increased levels of physical activity. ${ }^{54}$ Control group participants are not asked to refrain from physical activity and may enrol in exercise programmes outside of the study. The use of a sham exercise intervention for the control group was discussed, but deemed unsuitable in terms of use of resources in physiotherapy primary care.

Exercise intensity has emerged as a vital component of exercise programmes with compelling evidence of superior physiological adaptations following vigorous exercise. Indeed, a study in coronary heart disease reports superior effects in patients that exercise at the higher end of the HIIT intensity spectrum. ${ }^{55}$ In our study, $\mathrm{HR}_{\text {peak }}$ is derived from CPET and exercise intensity is measured as percentage of $\mathrm{HR}_{\text {peak }}$ and Borg RPE 6-20. $\mathrm{HR}_{\text {peak }}$ can deviate between repeated exercise tests and be underestimated in cases of peripheral fatigue. ${ }^{34} 49$ Thus, we cannot rule out that using $\mathrm{HR}_{\text {peak }}$ from a single CPET may lead to inaccurate prescription of HIIT HR zone.

Wearable fitness trackers have the potential to improve physical activity levels, especially in sedentary individuals. ${ }^{56}$ In our trial, all patients in the HIIT group are provided with a personal fitness watch to monitor HR during exercise and further use of the fitness watch outside of exercise sessions is at the patient's preference. Feedback and cues from the fitness watch can potentially instigate physical activity behavioural changes that act in concert with the HIIT intervention.

In summary, ExeHeart is a pragmatic trial, aiming to generate applicable knowledge on the potential cardioprotective effect of HIIT in the context of IJD, the feasibility of HIIT in physiotherapy primary care and the validity of eCRF models.

\section{Author affiliations}

${ }^{1}$ Norwegian National Advisory Unit on Rehabilitation in Rheumatology, Division of Rheumatology and Research, Diakonhjemmet Hospital, Oslo, Norway

${ }^{2}$ Institute of Health and Society, Faculty of Medicine, University of Oslo, Oslo, Norway

${ }^{3}$ Preventive Cardio-Rheuma Clinic, Division of Rheumatology and Research, Diakonhjemmet Hospital, Oslo, Norway 
${ }^{4}$ Department of vascular surgery, University of Oslo Faculty of Medicine, Oslo, Norway

${ }^{5}$ Department of Pharmacy, University of Oslo, Oslo, Norway

${ }^{6}$ Diakonhjemmet Hospital Pharmacy, Diakonhjemmet Hospital, Oslo, Norway ${ }^{7}$ Division of Rheumatology and Research, Diakonhjemmet Hospital, Oslo, Norway ${ }^{8}$ Patient advisory board, Division of Rheumatology and Research, Diakonhjemmet Hospital, Oslo, Norway

${ }^{9}$ Department of Nutrition and Dietetics, University of Thessaly, Volos, Thessaly, Greece

Correction notice This article has been has been corrected since it was first published. The figure 1 has been corrected.

Acknowledgements We thank the patients willing to participate in the ExeHeart trial and the Norwegian League against Rheumatism/Norwegian Rheumatism Association for collaboration in the planning of the study. Furthermore, we thank nurse Anne Stormyr Eirheim for training in measures of arterial stiffness and valuable help in patient enrollment. Lastly, we owe thanks to physiotherapist Henrik Gifstad at Atlet Fysio, physiotherapist Paal Drummond at Volvat and musculoskeletal physiotherapists Fred Hatlebrekke and Øyvind Erås at Hans\&Olaf Fysioterapi AS for their valuable enthusiasm and commitment in the ExeHeart trial.

Contributors KRN: study design, acquisition of data, drafting the article and final approval of the manuscript. AGS: study design, acquisition of data, critical revision and final approval of the manuscript. ATT, HD, JH, GSM, JSe, JSk, TB and KV: study design, critical revision and final approval of the manuscript. CF: acquisition of data, critical revision and final approval of the manuscript. No intended use of professional writers.

Funding This work is supported by the Dam foundation (grant number 2021/ F0347439), Dr Trygve Gythfeldt and Wife research fund (June 2021, no grant number), the Norwegian Rheumatism Association (November 2021, no grant number) and the Norwegian Health Association (25576).

Disclaimer The funding sources have no role in the design, analysis and interpretation of the study.

Competing interests AGS has received lecture honoraria from AbbVie, Novartis, Bayer, Eli Lilly and Sanofi. AGS is secretary of ESC Cardiovascular Pharmacotherapy working group, nucleus member of EACP Risk Factor Management and Primary care and steering committee member for ATACC-RA, all gratuitous. GSM has received lecture honoraria from Novartis. $\mathrm{JH}$ has received lecture honoraria from Amgen. KRN, HD, KV, JSe, CF, JSk, TB and ATT have nothing to disclose.

Patient consent for publication Not applicable.

Provenance and peer review Not commissioned; externally peer reviewed.

Supplemental material This content has been supplied by the author(s). It has not been vetted by BMJ Publishing Group Limited (BMJ) and may not have been peer-reviewed. Any opinions or recommendations discussed are solely those of the author(s) and are not endorsed by BMJ. BMJ disclaims all liability and responsibility arising from any reliance placed on the content. Where the content includes any translated material, BMJ does not warrant the accuracy and reliability of the translations (including but not limited to local regulations, clinical guidelines, terminology, drug names and drug dosages), and is not responsible for any error and/or omissions arising from translation and adaptation or otherwise.

Open access This is an open access article distributed in accordance with the Creative Commons Attribution Non Commercial (CC BY-NC 4.0) license, which permits others to distribute, remix, adapt, build upon this work non-commercially, and license their derivative works on different terms, provided the original work is properly cited, appropriate credit is given, any changes made indicated, and the use is non-commercial. See: http://creativecommons.org/licenses/by-nc/4.0/.

\section{ORCID iD}

Kristine Røren Nordén http://orcid.org/0000-0001-6664-7542

\section{REFERENCES}

1 Sieper J, Poddubnyy D. Axial spondyloarthritis. Lancet 2017;390:73-84.

2 Scott DL, Wolfe F, Huizinga TWJ. Rheumatoid arthritis. Lancet 2010;376:1094-108.

3 Agca R, Heslinga SC, Rollefstad S, et al. EULAR recommendations for cardiovascular disease risk management in patients with rheumatoid arthritis and other forms of inflammatory joint disorders: 2015/2016 update. Ann Rheum Dis 2017;76:17-28.

4 Holmqvist M, Ljung L, Askling J. Acute coronary syndrome in newonset rheumatoid arthritis: a population-based nationwide cohort study of time trends in risks and excess risks. Ann Rheum Dis 2017;76:1642-7.

$5 \mathrm{Kim} \mathrm{JH}$, Choi IA. Cardiovascular morbidity and mortality in patients with spondyloarthritis: a meta-analysis. Int J Rheum Dis $2021 ; 24: 477-86$

6 Kerola AM, Rollefstad S, Semb AG. Atherosclerotic cardiovascular disease in rheumatoid arthritis: impact of inflammation and antirheumatic treatment. Eur Cardiol 2021;16:e18.

7 Visseren FLJ, Mach F, Smulders YM, et al. 2021 ESC guidelines on cardiovascular disease prevention in clinical practice. Eur Heart $J$ 2021;42:3227-337.

8 Agca R, Heslinga SC, van Halm VP, et al. Atherosclerotic cardiovascular disease in patients with chronic inflammatory joint disorders. Heart 2016;102:790-5.

9 Wibetoe G, Ikdahl E, Rollefstad S, et al. Cardiovascular disease risk profiles in inflammatory joint disease entities. Arthritis Res Ther 2017;19:153.

10 Crowson CS, Rollefstad S, Ikdahl E, et al. Impact of risk factors associated with cardiovascular outcomes in patients with rheumatoid arthritis. Ann Rheum Dis 2018;77:48-54.

11 Ross R, Blair SN, Arena R, et al. Importance of assessing cardiorespiratory fitness in clinical practice: a case for fitness as a clinical vital sign: a scientific statement from the American heart association. Circulation 2016;134:e653-99.

12 Liff $\mathrm{MH}$, Hoff $\mathrm{M}$, Wisloff $\mathrm{U}$, et al. Reduced cardiorespiratory fitness is a mediator of excess all-cause mortality in rheumatoid arthritis: the Trøndelag health study. RMD Open 2021;7.

13 O'Dwyer T, O'Shea F, Wilson F. Decreased physical activity and cardiorespiratory fitness in adults with ankylosing spondylitis: a cross-sectional controlled study. Rheumatol Int 2015;35:1863-72.

14 Mackey RH, Kuller LH, Moreland LW. Update on cardiovascular disease risk in patients with rheumatic diseases. Rheum Dis Clin North Am 2018;44:475-87.

15 Metsios GS, Koutedakis Y, Veldhuijzen van Zanten JJCS, et al. Cardiorespiratory fitness levels and their association with cardiovascular profile in patients with rheumatoid arthritis: a crosssectional study. Rheumatology 2015;54:2215-20.

16 Ikdahl E, Wibetoe G, Rollefstad S, et al. Guideline recommended treatment to targets of cardiovascular risk is inadequate in patients with inflammatory joint diseases. Int J Cardiol 2019;274:311-8.

17 Rollefstad S, Ikdahl E, Wibetoe G, et al. An international audit of the management of dyslipidaemia and hypertension in patients with rheumatoid arthritis-results from 19 countries. Eur Heart $J$ Cardiovasc Pharmacother 2021. doi:10.1093/ehjcvp/pvab052. [Epub ahead of print: $07 \mathrm{Jul} 2021]$.

18 Crowson CS, Rollefstad S, Kitas GD, et al. Challenges of developing a cardiovascular risk calculator for patients with rheumatoid arthritis. PLoS One 2017;12:e0174656.

19 Nes BM, Janszky I, Vatten LJ, et al. Estimating V.O 2peak from a nonexercise prediction model: the HUNT study, Norway. Med Sci Sports Exerc 2011;43:2024-30.

20 Riebe D, Ehrman JK, Liguori G. ACSM's guidelines for exercise testing and prescription. 10 edn. Philadelphia: Wolters Kluwer, 2018.

21 Semb AG, Ikdahl E, Wibetoe G, et al. Atherosclerotic cardiovascular disease prevention in rheumatoid arthritis. Nat Rev Rheumatol 2020;16:361-79.

22 Metsios GS, Fenton SA, Moe HR, et al. Implementation of physical activity into routine clinical pracTice in rheumatic musculoskeletal disease: the IMPACT-RMD study protocol and rationale. Mediterr J Rheumatol 2019;30:231-6.

23 Sveaas SH, Bilberg A, Berg IJ, et al. High intensity exercise for 3 months reduces disease activity in axial spondyloarthritis (axSpA): a multicentre randomised trial of 100 patients. Br J Sports Med 2020;54:292-297.

24 de Jong Z, Munneke M, Kroon HM, et al. Long-term follow-up of a high-intensity exercise program in patients with rheumatoid arthritis. Clin Rheumatol 2009;28:663-71.

25 Thomsen RS, Nilsen TIL, Haugeberg G, et al. Impact of high-intensity interval training on disease activity and disease in patients with psoriatic arthritis: a randomized controlled trial. Arthritis Care Res 2019;71:530-7.

26 Sveaas SH, Smedslund G, Hagen KB, et al. Effect of cardiorespiratory and strength exercises on disease activity in patients with inflammatory rheumatic diseases: a systematic review and meta-analysis. Br J Sports Med 2017;51:1065-72.

27 Metsios GS, Moe RH, Kitas GD. Exercise and inflammation. Best Pract Res Clin Rheumatol 2020;34:101504. 
28 Karlsen T, Aamot I-L, Haykowsky M, et al. High intensity interval training for maximizing health outcomes. Prog Cardiovasc Dis 2017;60:67-77.

29 Batacan RB, Duncan MJ, Dalbo VJ, et al. Effects of high-intensity interval training on cardiometabolic health: a systematic review and meta-analysis of intervention studies. Br J Sports Med 2017;51:494503.

30 Weston KS, Wisløff U, Coombes JS. High-Intensity interval training in patients with lifestyle-induced cardiometabolic disease: a systematic review and meta-analysis. Br J Sports Med 2014;48:1227-34.

31 Metsios GS, Moe RH, van der Esch M, et al. The effects of exercise on cardiovascular disease risk factors and cardiovascular physiology in rheumatoid arthritis. Rheumatol Int 2020;40:347-357.

32 Biddle SJH, Batterham AM. High-Intensity interval exercise training for public health: a big hit or shall we hit it on the head? Int J Behav Nutr Phys Act 2015;12:95.

33 Semb AG, Ikdahl E, Hisdal J, et al. Exploring cardiovascular disease risk evaluation in patients with inflammatory joint diseases. Int $J$ Cardiol 2016;223:331-6.

34 Decato TW, Bradley SM, Wilson EL, et al. Repeatability and meaningful change of CPET parameters in healthy subjects. Med Sci Sports Exerc 2018;50:589-95.

35 American Thoracic Society; American College of Chest Physicians. ATS/ACCP statement on cardiopulmonary exercise testing. Am J Respir Crit Care Med 2003;167:211-77.

36 Graham BL, Steenbruggen I, Miller MR, et al. Standardization of spirometry 2019 update. An official American thoracic Society and European respiratory Society technical statement. Am J Respir Crit Care Med 2019;200:e70-88.

37 Borg GA. Psychophysical bases of perceived exertion. Med Sci Sports Exerc 1982;14:377-81.

38 Balke B, Ware RW. An experimental study of physical fitness of air force personnel. U S Armed Forces Med J 1959;10:675-88.

39 Edvardsen E, Hem E, Anderssen SA. End criteria for reaching maximal oxygen uptake must be strict and adjusted to sex and age: a cross-sectional study. PLoS One 2014;9:e85276.

40 van Gammeren AJ, van Gool N, de Groot MJM, et al. Analytical performance evaluation of the Cobas 6000 analyzer - special emphasis on trueness verification. Clin Chem Lab Med 2008;46:863-71.

41 van Riel PLCM, Renskers L. The disease activity score (DAS) and the disease activity score using 28 joint counts (DAS28) in the management of rheumatoid arthritis. Clin Exp Rheumatol 2016;34:S40-4.

42 Kerschbaumer A, Smolen JS, Aletaha D. Disease activity assessment in patients with psoriatic arthritis. Best Pract Res Clin Rheumatol 2018;32:401-14.

43 van der Heijde D, Lie E, Kvien TK, et al. ASDAS, a highly discriminatory ASAS-endorsed disease activity score in patients with ankylosing spondylitis. Ann Rheum Dis 2009;68:1811-8.

44 Taylor JL, Holland DJ, Keating SE, et al. Adherence to highintensity interval training in cardiac rehabilitation: a review and recommendations. J Cardiopulm Rehabil Prev 2021;41:61-77.

45 van der Maas A, Lie E, Christensen R, et al. Construct and criterion validity of several proposed DAS28-based rheumatoid arthritis flare criteria: an OMERACT cohort validation study. Ann Rheum Dis 2013;72:1800-5.
46 Helliwell PS, Tillett W, Waxman R, et al. Evaluation and validation of a patient-completed psoriatic arthritis flare questionnaire. J Rheumatol 2021;48:1268-71.

47 Molto A, Gossec L, Meghnathi B, et al. An Assessment in SpondyloArthritis International Society (ASAS)-endorsed definition of clinically important worsening in axial spondyloarthritis based on ASDAS. Ann Rheum Dis 2018;77:124-7.

48 Myers J, Forman DE, Balady GJ, et al. Supervision of exercise testing by nonphysicians: a scientific statement from the American heart association. Circulation 2014;130:1014-27.

49 Taylor JL, Holland DJ, Spathis JG, et al. Guidelines for the delivery and monitoring of high intensity interval training in clinical populations. Prog Cardiovasc Dis 2019;62:140-146.

50 Liff MH, Hoff M, Fremo T, et al. An estimation model for cardiorespiratory fitness in adults with rheumatoid arthritis. Med Sci Sports Exerc 2020;52:1248-55

51 Boutron I, Moher D, Altman DG, et al. Extending the CONSORT statement to randomized trials of nonpharmacologic treatment: explanation and elaboration. Ann Intern Med 2008;148:295-309.

52 Slade SC, Dionne CE, Underwood M, et al. Consensus on exercise reporting template (CERT): explanation and elaboration statement. $\mathrm{Br}$ J Sports Med 2016;50:1428-37.

53 Chan A-W, Tetzlaff JM, Gøtzsche PC, et al. Spirit 2013 explanation and elaboration: guidance for protocols of clinical trials. $B M J$ 2013;346:e7586.

54 Stensvold D, Viken H, Steinshamn SL, et al. Effect of exercise training for five years on all cause mortality in older adultsthe generation 100 study: randomised controlled trial. BMJ 2020;371:m3485.

55 Moholdt T, Madssen E, Rognmo Øivind, Rognmo O, et al. The higher the better? interval training intensity in coronary heart disease. J Sci Med Sport 2014;17:506-10.

56 Nuss K, Moore K, Nelson T, et al. Effects of motivational interviewing and wearable fitness Trackers on motivation and physical activity: a systematic review. Am J Health Promot 2021;35:226-35.

57 Busija L, Ackerman IN, Haas R, et al. Adult measures of general health and health-related quality of life. Arthritis Care Res 2020;72 Suppl 10:522-64

58 Devlin NJ, Shah KK, Feng Y, et al. Valuing health-related quality of life: an EQ-5D-5L value set for England. Health Econ 2018;27:7-22.

59 Gossec L, Paternotte S, Aanerud GJ, et al. Finalisation and validation of the rheumatoid arthritis impact of disease score, a patient-derived composite measure of impact of rheumatoid arthritis: a EULAR initiative. Ann Rheum Dis 2011;70:935-42.

60 Gossec L, de Wit M, Kiltz U, et al. A patient-derived and patientreported outcome measure for assessing psoriatic arthritis: elaboration and preliminary validation of the psoriatic arthritis impact of disease (PsAID) questionnaire, a 13-country EULAR initiative. Ann Rheum Dis 2014;73:1012-9.

61 Ogdie A, Duarte-García A, Hwang M, et al. Measuring outcomes in axial spondyloarthritis. Arthritis Care Res 2020;72 Suppl 10:47-71.

62 Kurtze N, Rangul V, Hustvedt B-E, et al. Reliability and validity of selfreported physical activity in the Nord-Trøndelag health study: Hunt 1. Scand J Public Health 2008;36:52-61.

63 Gecht MR, Connell KJ, Sinacore JM, et al. A survey of exercise beliefs and exercise habits among people with arthritis. Arthritis Care Res 1996;9:82-8. 